\title{
Surgeon condemns crude data on outcomes for causing "debacle"
}

Clarification-Part of a quote from Simon Payne was taken out of context in this News story (BMJ 2013;347:f4299, doi:10. 1136/bmj.f4299). The quote from Payne in the sixth paragraph could be incorrectly interpreted as suggesting that surgeons should not think about the risk of complications when assessing patients for surgery. Payne would like to make it clear that he was emphasising one of the negative aspects of producing performance league tables using crude data is that they could make surgeons think about their position on such tables, when their only consideration should be whether patients are likely to benefit from surgery.

Cite this as: BMJ 2013;347:f4398

๑ BMJ Publishing Group Ltd 2013 